\title{
The Effect of Plasmid R391 and Other IncJ Plasmids on the Survival of Escherichia coli After UV Irradiation
}

\author{
By J. TONY PEMBROKE*† AND EVELYN STEVENS \\ Department of Microbiology, University College, Galway, Ireland
}

(Received 12 December 1983)

\begin{abstract}
The presence of the IncJ plasmids R391, R997, R705, R706, R748 and R749 was shown to sensitize Escherichia coli $\mathrm{AB} 1157$ and both its $u v r A$ and lexA derivatives to UV irradiation. No alteration in post-irradiation survival was observed in a $r e c A$ mutant containing these plasmids, compared with the non-plasmid-containing $r e c A$ strain. Analysis of recombination frequency in $\mathrm{Hfr}$ crosses to $\mathrm{rec} \mathrm{A}^{+}$cells containing plasmid $\mathrm{R} 391$ indicated a reduction in recombination frequency compared with that obtained in similar crosses to a non-plasmid-containing strain. This effect was not due to plasmid-encoded restriction or entry exclusion systems and therefore must be considered as a real block in recombination. When cells containing plasmid R391 were irradiated and allowed to photoreactivate, an increase in survival was observed which was comparable to that observed in the non-plasmid-containing derivative. This indicated that postirradiation processing of UV-induced damage, or lack of such processing, by mechanisms other than photoreactivation was responsible for the UV sensitivity associated with plasmid R391.
\end{abstract}

\section{INTRODUCTION}

Many plasmids derived from various genera have been shown to affect post-UV irradiation survival of Escherichia coli (Molina et al., 1979; Pinney, 1980; Ando \& Arai, 1980; Chernin \& Miroyan, 1981), Pseudomonas aeruginosa (Lehrbach et al., 1977), Streptococcus faecalis (Miehl et al., 1980) and Salmonella typhimurium (Walker, 1978). Of the plasmids which affect post-irradiation survival in E. coli, most reports have centred on plasmids which enhance the survival of the host (Chernin \& Miroyan, 1981). One of the best-studied plasmids of this type, pKM101, has been shown to encode an analogue of $u m u C$, a gene involved directly in error-prone repair (Walker \& Dobson, 1979). It has been proposed that the enhanced survival associated with the presence of pKM101 is due to an enhancement of the cells' error-prone repair system (Walker \& Dobson, 1979).

There have also been reports of plasmids which decrease the survival of their host after UV irradiation (March \& Smith, 1969; Siccardi, 1969; Khmel et al., 1981), and although it has been postulated that such an effect may reflect lack of repair capacity, such effects have not been further characterized.

We report here an initial characterization of the effect of plasmid R391 and other plasmids of the incompatibility group $\mathbf{J}$ on the post-irradiation survival of E. coli K12.

\section{METHODS}

Bacterial strains and plasmids. These are listed in Table 1. Plasmids were transferred from strain JTP686 as described by Miller (1972). Antibiotics (Sigma grade) were used at the following concentrations : kanamycin (Kan) $30 \mu \mathrm{g} \mathrm{ml}^{-1}$, ampicillin (Amp) $50 \mu \mathrm{g} \mathrm{ml}^{-1}$, rifampicin (Rif) $100 \mu \mathrm{g} \mathrm{ml}^{-1}$, streptomycin (Str) $100 \mu \mathrm{g} \mathrm{ml}^{-1}$ and mercuric chloride $(\mathrm{Hg}) 20 \mu \mathrm{g} \mathrm{ml} \mathrm{m}^{-1}$.

UV survival. Overnight cultures in Luria broth (Miller, 1972) were grown with gentle shaking at $37^{\circ} \mathrm{C}$ and reinoculated into the same medium until viable counts between 2 and $3 \times 10^{8}$ were reached $\left(A_{540}=0 \cdot 1\right.$ on a

$\dagger$ Present address: Department of Industrial Chemistry, National Institute for Higher Education, Limerick, Ireland.

0022-1287/84/0001-1651 \$02.00 (C) 1984 SGM 
Table 1. Bacterial strains and plasmids

Strain Genotype Source

\begin{tabular}{|c|c|c|}
\hline AB 1157 & thr-1 leu-6 thi-1 argE3 his-4 proA2 lac $Y 1$ & \\
\hline AB 1886 & $\begin{array}{l}\text { galK } 2 \text { mtl-1 } x y l-5 \text { ara- } 14 \text { rpsL ts } 33 \text { supE } 44 \\
\text { as AB } 1157 \text { but uvrA6 }\end{array}$ & B. Bachman, E. coli Genetic Stock Center, \\
\hline AB2463 & as $\mathrm{AB} 1157$ but recA13 & \\
\hline AB2494 & as AB1157 but lexAl metBI $\mathrm{arg}^{+} \mathrm{leu}^{+}$ & \\
\hline JTP686 & $r p o B \lambda^{r}$ & This laboratory \\
\hline $\mathrm{JC} 158$ & serA6 HfrPO1 lacI22 thi-1 rel-1 & $\begin{array}{l}\text { A. J. Clark, Dept of Molecular Biology, } \\
\text { University of California, Berkeley }\end{array}$ \\
\hline
\end{tabular}

Plasmid Characteristics Source

$\left.\begin{array}{ll}\text { R391 } & \mathrm{Hg}^{\mathrm{r}} \mathrm{Tra}^{+} \mathrm{Km}^{\mathrm{r}} \\ \text { R706 } & \text { as R391 } \\ \text { R705 } & \text { as R391 } \\ \text { R748 } & \text { as R391 } \\ \text { R749 } & \text { as R391 } \\ \text { R391-3b-1 } & \begin{array}{l}\mathrm{Sm}^{\mathrm{r}} \mathrm{Sp}^{\mathrm{r}} \mathrm{Hg}^{\mathrm{r}} \\ \text { R997 }\end{array} \\ \mathrm{Ap}^{r} \mathrm{Sm}^{\mathrm{r}} \mathrm{Su}^{\mathrm{r}}\end{array}\right\} \begin{aligned} & \text { R. W. Hedges, Royal Postgraduate Medical } \\ & \text { School, London }\end{aligned}$

Vitatron spectrophotometer). Cells were collected by centrifugation, washed twice with $0 \cdot 85 \%(w / v)$ saline and resuspended in $0.85 \%$ saline, or in M9 medium without growth requirements (Miller, 1972) in the case of photoreactivation experiments. After starvation by shaking for $30 \mathrm{~min}, 9 \mathrm{ml}$ samples were irradiated using a Griffin and George UV source with dose rate determined by actinometry (Jagger, 1976) or using a UV radiometer (UV Products Inc., San Gabriel, Calif., USA). After irradiation, cells were plated on Luria broth agar with or without antibiotic under yellow lighting and incubated in the dark at $37^{\circ} \mathrm{C}$.

Photoreactivation. Strains after irradiation at $9 \mathrm{~J} \mathrm{~m}^{-2}$ in M9 medium were tested for UV survival as described. Samples were photoreactivated essentially as described by Williams et al. (1979) for various times. Control samples unirradiated or irradiated without photoreactivation were also titrated for viable fraction.

Recombination frequencies. Hfr $\times \mathrm{F}^{-}$crosses to strains with and without plasmid R391 were carried out as described by Miller (1972), using JC158 as the donor and selecting for recombination of the threonine locus in recipients auxotrophic for threonine. Tests for plasmid-encoded restriction of Hfr DNA were as described by Coetzee et al. (1972). To determine if plasmid-encoded entry exclusion was present in R391-containing cells and frequency of transfer of $F^{\prime} l a c T n 3$ to strains with and without plasmid R391 was examined. Transfer was carried out as described by Miller (1972).

\section{RESULTS}

Effect of IncJ plasmids on the UV survival of E. coli

Figure 1 illustrates the effect of the IncJ plasmids R391, R997, R705, R706, R748 and R749 on the post-UV survival of $E$. coli strain AB1157. All these plasmids sensitized their host to UV irradiation. The extent of the sensitization appeared to be similar for each of the plasmids over the particular UV dose range examined. The possibility that the decreased survival reflected a lack of repair capacity was examined by analysing the effect of these six IncJ plasmids in repairdeficient backgrounds. It is proposed that if the IncJ plasmids were affecting the operation of a particular repair process then if the plasmid were present in strains deficient in such a process, there should no longer be a plasmid effect. Three main repair processes have been defined in $E$. coli (Witkin, 1976) - photoreactivation, which can be abolished by incubation in the dark or by mutation at the phr locus, excision repair, which can be abolished by mutation at one of three loci, $u v r A, u v r B$ or $u v r C$ and finally post-replication repair which can be abolished by mutation at the rec $A$ locus.

Irradiation of repair-proficient strains containing these six plasmids with post-irradiation incubation in the dark was shown to sensitize such strains (Fig. 1), indicating the ability of these plasmids to sensitize in the absence of photoreactivation. Figure 2 illustrates the effect of the six IncJ plasmids on the survival of strain $\mathrm{AB} 1886$ ( $u v r A)$ : all the plasmids increased the sensitivity of this derivative to UV. Figure 3 illustrates the survival of strain AB2463 (recA) containing the six IncJ plasmids. No increase in sensitivity could be observed with any of the plasmids tested, 


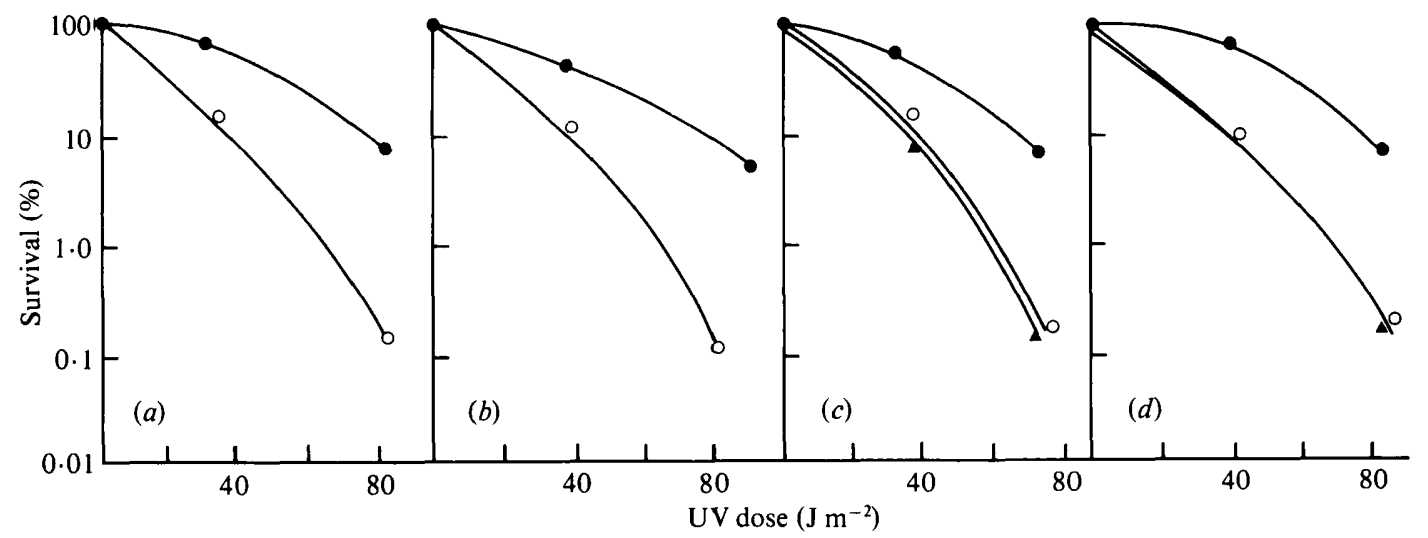

Fig. 1. Effect of six IncJ plasmids on the survival of E. coli AB1157 after UV irradiation. (a) AB1157; O, AB1157(R391). (b) O, AB1157; O, AB1157(R997). (c) O, AB1157; O, AB1157(R705); $\Delta, \mathrm{AB} 1157(\mathrm{R} 706)$. (d) O, AB1157; O, AB1157(R748); $\Delta, \mathrm{AB} 1157(\mathrm{R} 749)$. Each experiment was done at least five times; the values shown are the means (this also applies to Figs 2-6).

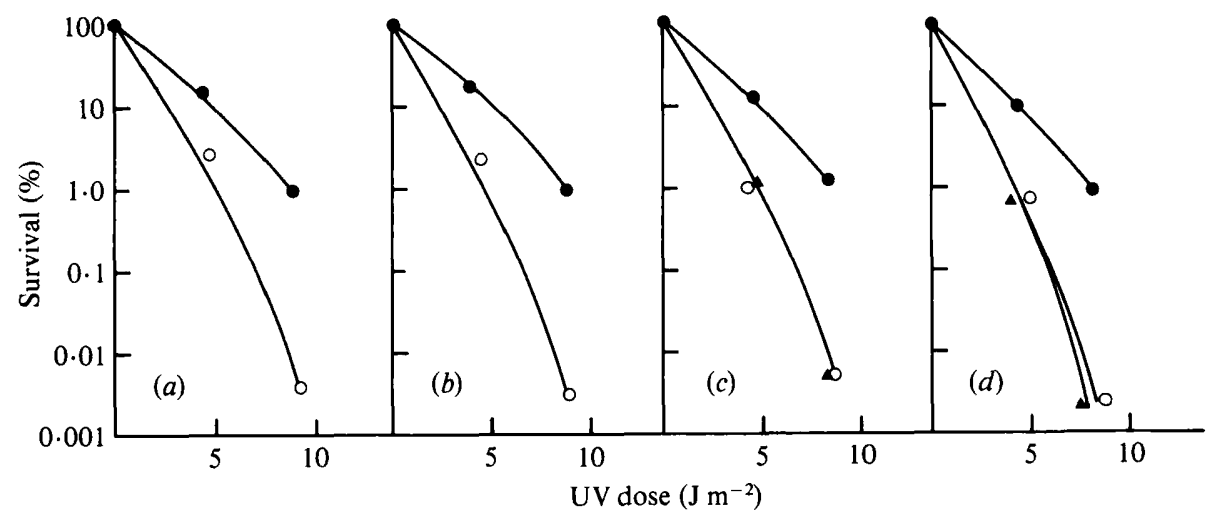

Fig. 2. Effect of IncJ plasmids on the survival of $E$. coli AB 1886 (uvrA) after UV irradiation. (a) AB1886; O, AB1886(R391). (b) O, AB1886; O, AB1886(R997). (c) , AB1886; O, AB1886(R705); $\triangle$, AB1886(R706). (d) O, AB1886; O, AB1886(R748); $\triangle$, AB1886(R749).

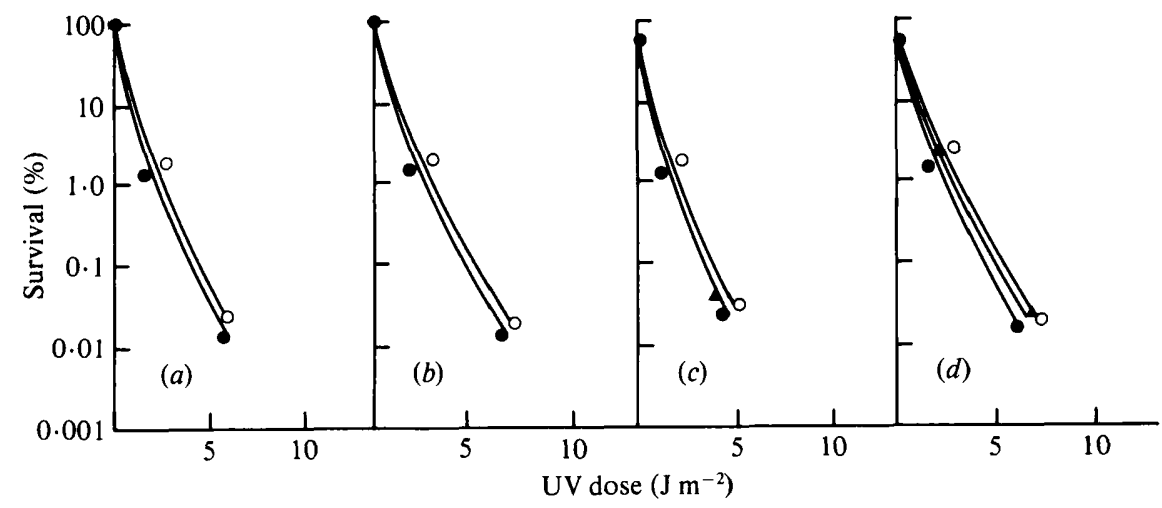

Fig. 3. Effect of IncJ group plasmids on the survival of E. coli AB2463 (rec A) after UV irradiation. (a) AB2463; O, AB2463(R391). (b) O, AB2463; O, AB2463(R997). (c) O, AB2463; $\bigcirc$, AB2463(R705); $\Delta$, AB2463(R706). (d) O, AB2463; O, AB2463(R748); A, AB2463(R749). 


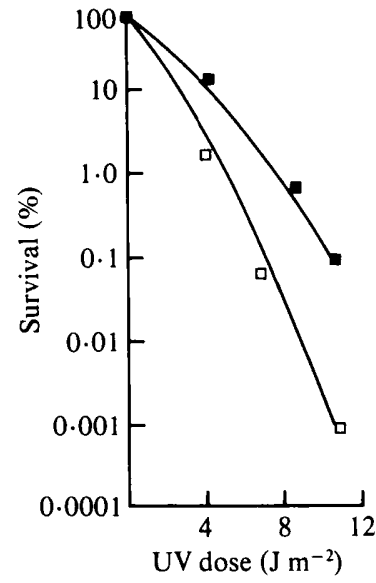

Fig. 4

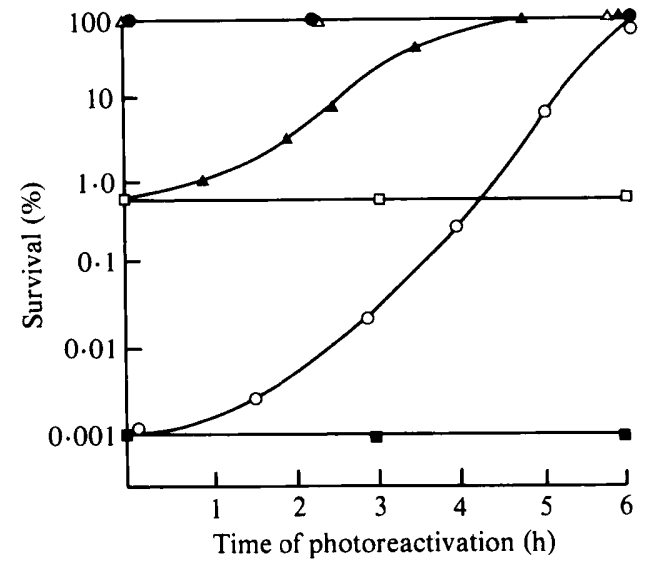

Fig. 5

Fig. 4. Effect of plasmid R391 on the survival of E. coli AB2494 (lexA) after UV irradiation. AB2494; $\square$, AB2494(R391).

Fig. 5. Effect of photoreactivating light on the post-UV irradiation survival of strain AB1886 with and without plasmid R391. , AB1886 unirradiated; $\square, A B 1886$ irradiated but without photoreactivation; $\Delta, A B 1886$ irradiated and photoreactivated; $\triangle, A B 1886(R 391)$ unirradiated; $A, A B 1886(R 391)$ irradiated but without photoreactivation; $\mathrm{O}, \mathrm{AB} 1886(\mathrm{R} 391)$ irradiated and photoreactivated.

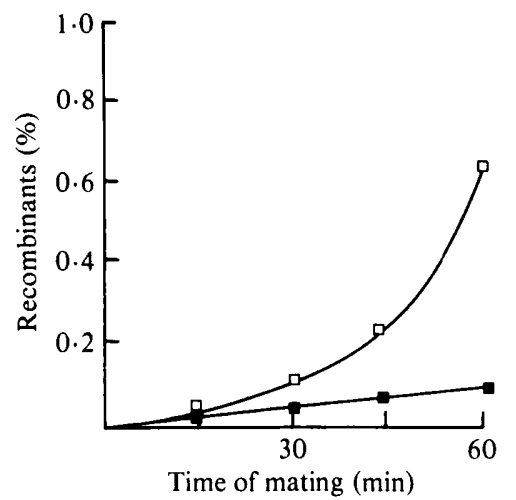

Fig. 6. Effect of plasmid $\mathrm{R} 391$ on recombinants recovered in $\mathrm{Hfr} \times \mathrm{F}^{-}$crosses. The recombination frequency was calculated as the percentage of threonine prototrophs recovered per recipient. $\square, \mathrm{JC} 158$ $\times$ AB1157; $\mathbf{D}, \mathrm{JC1} 158 \times \mathrm{AB} 1157(\mathrm{R} 391)$.

in fact they all produced a slight but reproducible increase in resistance. The apparent lack of effect of the IncJ plasmids in a $\operatorname{rec} A$ background suggests that a $r e c A^{+}$-dependent process was being affected by the presence of IncJ plasmids.

The effect of the prototype IncJ plasmid R391 (Coetzee et al., 1972) was examined in strain AB2494 (lexA) (Fig. 4) and found to sensitize this derivative, indicating a lexA independence for the effect.

\section{Effect of photoreactivation on the UV sensitivity associated with plasmid R391}

Excision-deficient derivatives held in non-growing conditions were irradiated and survival was monitored after exposure to photoreactivating light for various times after UV irradiation (Fig. 5). Although strains containing plasmid R391 were more sensitive to UV irradiation, allowing photoreactivation to occur could reverse this sensitivity and restore viability to the level of the non-plasmid-containing strain after photoreactivation. 


\section{Effect of plasmid $R 391$ on recombination levels in Hfr crosses}

The apparent $\operatorname{rec} A$ dependence and lex $A$ independence suggests that the effect of plasmid $\mathrm{R} 391$ might be at the level of a $\operatorname{rec} A$-dependent process not related to the inducible $\operatorname{rec} A^{+}$dependent processes (Witkin, 1976). For this reason the recombination levels in R391containing cells were examined. Figure 6 illustrates the effect of R391 on threonine recombinants recovered in $\mathrm{Hfr}$ crosses between $\mathrm{JC} 158$ and the poly-auxotrophic strain $\mathrm{AB} 1157$ containing plasmid R391. The presence of plasmid R391 considerably reduced the frequency of recombinants recovered. This apparent block in recombination ability was not due to plasmidencoded restriction since no reduction in the titre of $\lambda$ could be detected when titrated on R391containing strains (data not shown). The frequency of transfer of $F^{\prime} l a c \operatorname{Tn} 3$ to R391-containing strains was found to be similar to transfer frequencies to the non-plasmid-containing strains, indicating absence of plasmid-encoded entry exclusion of $F^{\prime}$-factor DNA.

\section{DISCUSSION}

It has been shown that six IncJ plasmids, R391, R997, R705, R706, R748 and R749, sensitize E. coli $\mathrm{K} 12$ to UV irradiation. The nature of this sensitization has been examined. No evidence could be found for phage induction of lytic phenomena (Pembroke, 1982). It was thus proposed that lack of repair capacity was responsible for the UV sensitivity associated with the presence of the IncJ plasmids (Pembroke, 1982).

The sensitization appears to be independent of the photoreactivation and excision-repair processes but dependent on the $\operatorname{rec} A^{+}$genotype as judged by inability of the IncJ plasmids to sensitize a $r e c A$ derivative. Since the $r e c A$ genotype is extremely pleiotropic (Witkin, 1976) the effect of plasmid R391 was examined in a lexA background. Because of the ability of plasmid $\mathrm{R} 391$ to sensitize a lex $A$ derivative it is proposed that the lack of repair capacity is not at the level of the $\operatorname{rec} A^{+}$-dependent, inducible functions but rather at the level of some other $r e c A^{+}$dependent process.

Studies using post-irradiation photoreactivation suggested that if photoreactivation is allowed to take place, a reversal of the initial sensitivity associated with the presence of plasmid R391 can occur. This may be interpreted as suggesting that it is the aberrant processing of UVinduced lesions by processes other than photoreactivation in cells containing plasmid R 391 that is responsible for the UV sensitivity. The requirement for the $\mathrm{rec}^{+}$genotype suggests that this aberrant processing may be at the level of a $\operatorname{rec} A^{+}$-dependent process.

It has been proposed that the major pathways of $r e c A^{+}$-dependent repair are recombinational (Clark, 1973). Several recombination-deficient mutants have been isolated (Horii \& Clark, 1973) and at least two pathways of recombination operate in E. coli (Clark, 1973). Analysis of the recombination ability of recombination-proficient strains carrying plasmid R391 suggests that recombination frequencies are reduced significantly in cells containing plasmid $R 391$. This reduced recombination ability appears to be a real block in recombination since no evidence could be found for plasmid-encoded restriction or entry exclusion of incoming Hfr DNA. It is not clear at present whether this recombination deficiency is related to the UV sensitivity. However, studies using the transcriptional probe Mu d(lac amp) (Casadaban \& Cohen, 1979) suggest that this is the case (J. T. Pembroke, unpublished).

It thus appears that the UV sensitivity associated with the presence of plasmid R391 may be related to a lowering of recombination ability. This lowering in recombination frequency appears to occur in the absence of DNA damage, as recipients in $\mathrm{Hfr}$ crosses were unirradiated. The mechanism of UV sensitivity associated with plasmid R391 may be similar to that of all IncJ plasmids, although this is as yet uncertain. However, because of the narrow distribution of these plasmids, it would appear that they may all have a common origin (Hedges et al., 1975). Work is in progress to further characterize the effect of plasmid R391.

We would like to thank Deirdre Cunningham, Maire Sweeney, Martin Curran, Cees A. Van Sluis, Jourica Brandsma, Eva Van de Berg and Pieter Van de Putte for helpful discussions. One of us (J.T.P.) was supported in part by an EMBO short-term fellowship. 


\section{REFERENCES}

ANDo, T. \& ARal, T. (1980). Mechanism of plasmid mediated enhancement of ultra violet resistance and mutability. Keijo Journal of Medicine 29, 55-66.

Casadaban, M. J. \& Cohen, S. N. (1979). Lactose genes fused to exogenous promoters in one step using a Mu-lac bacteriophage: in vivo probe for transcriptional control sequences. Proceedings of the National Academy of Sciences of the United States of America 76, 4530-4533.

Chernin, L. S. \& Miroyan, V. S. (1981). Effect of plasmids on chromosome metabolism in bacteria. Plasmid 6, 119-140.

Clark, A. J. (1973). Recombination deficient mutants of E. coli and other bacteria. Annual Review of Genetics 7, 67-86.

Coetzee, J. N., Datta, N. \& Hedges, R. W. (1972). Rfactors from Proteus rettgeri. Journal of General Microbiology 72, 543-553.

Hedges, R. W., Jacob, A. E., Datta, N. \& Coetzee, J. N. (1975). Properties of plasmids produced by recombination between $\mathbf{R}$ factors of groups $\mathbf{J}$ and FII. Molecular and General Genetics 140, 289-302.

HoRII, Z. I. \& CLARK, A. J. (1973). Genetic analysis of the rec $F$ pathway of genetic recombination in $E$. coli $\mathrm{K} 12$ : isolation and characterization of mutants. Journal of Molecular Biology 80, 327-344.

JAGGER, J. (1976). Introduction to Research in Ultraviolet Photobiology. New Jersey: Prentice-Hall.

Khmel, I. A., Kopylov, V. M., Vorobjeva, I. P. \& Dolyanin, V. P. (1981). The influence of colicinogenic plasmids Col 1b-P9, Col la-CA55 and Col V$\mathrm{K} 30$ on the repair, mutagenesis and induction of colicin E1 synthesis. Molecular and General Genetics 181, 101-106.

Lehrbach, P., KING, A. H. C., LeE, B. T. D. \& JACOBY, G. A. (1977). Plasmid modification of radiation and chemical mutagen sensitivity in Pseudomonas aeruginosa. Journal of General Microbiology 98, 167-176.

MaRCH, E. B. \& SMITH, D. H. (1969). R-factors improving survival of Escherichia coli K12 after ultra-violet irradiation. Journal of Bacteriology 100 , 128-139.

Miehl, R., Miller, M. \& Yasbin, R. E. (1980). Plasmid mediated enhancement of UV resistance in Streptococcus faecalis. Plasmid 3, 128-134.

Miller, J. H. (1972). Experiments in Molecular Genetics. New York: Cold Spring Harbor Laboratory.

Molina, A. M., Babudri, N., Tamaro, M., Venturni, S. \& Monti-Bragadin, C. (1979). Enterobacteriaceae plasmids enhancing chemical mutagenesis and their distribution among incompatibility groups. FEMS Microbiology Letters 5, 33-37.

Pembroke, J. T. (1982). A study on the genetics and molecular biology of a plasmid which sensitizes its host to ultraviolet irradiation. $\mathrm{PhD}$ thesis, National University of Ireland.

PINNEY, R. J. (1980). Distribution among incompatibility groups of plasmids that confer UV mutability and UV resistance. Mutation Research 72, 155-159.

SICCARDI, A. G. (1969). Effect of R-factors and other plasmids on ultraviolet susceptibility and host cell reactivation property of Escherichia coli. Journal of Bacteriology 100, 337-346.

WALKER, G. C. (1978). Inducible reactivation and mutagenesis of UV irradiated bacteriophage P22 in Salmonella typhimurium LT2 containing the plasmid pKM101. Journal of Bacteriology 135, 415-421.

Walker, G.C. \& Dobson, D. P. (1979). Mutagenesis and repair deficiencies of $E$. coli umuC mutants are suppressed by the plasmid pKM101. Molecular and General Genetics 172, 17-24.

Williams, E., Lambert, J., O'Brien, P. A. \& Houghton, J. A. (1979). Evidence for dark repair of far UV light damage in the blue green alga Gloeocapsa alpicola. Photochemistry and Photobiology 29, 543-547.

WITKIN, E. M. (1976). UV mutagenesis and inducible DNA repair in E. coli. Bacteriological Reviews $\mathbf{4 0}$, 869-907. 